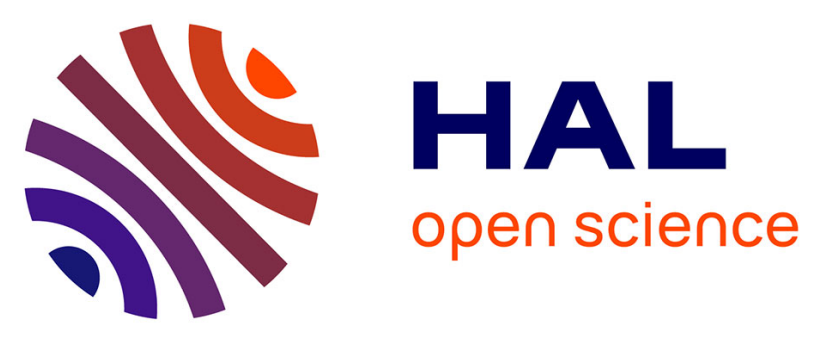

\title{
In vitro activity of doripenem and other carbapenems against contemporary Gram-negative pathogens isolated from hospitalised patients in the Asia-Pacific region: results of the COMPACT Asia-Pacific Study
}

K.J. Christiansen, M. Ip, H.B. Ker, M. Mendoza, L. Hsu, P. Kiratisin, A. Chongthaleong, I.S. Redjeki, A. Quintana, R. Flamm, et al.

\section{To cite this version:}

K.J. Christiansen, M. Ip, H.B. Ker, M. Mendoza, L. Hsu, et al.. In vitro activity of doripenem and other carbapenems against contemporary Gram-negative pathogens isolated from hospitalised patients in the Asia-Pacific region: results of the COMPACT Asia-Pacific Study. International Journal of Antimicrobial Agents, 2010, 36 (6), pp.501. 10.1016/j.ijantimicag.2010.08.002 . hal-00640449

\author{
HAL Id: hal-00640449 \\ https://hal.science/hal-00640449
}

Submitted on 12 Nov 2011

HAL is a multi-disciplinary open access archive for the deposit and dissemination of scientific research documents, whether they are published or not. The documents may come from teaching and research institutions in France or abroad, or from public or private research centers.
L'archive ouverte pluridisciplinaire HAL, est destinée au dépôt et à la diffusion de documents scientifiques de niveau recherche, publiés ou non, émanant des établissements d'enseignement et de recherche français ou étrangers, des laboratoires publics ou privés. 


\section{Accepted Manuscript}

Title: In vitro activity of doripenem and other carbapenems against contemporary Gram-negative pathogens isolated from hospitalised patients in the Asia-Pacific region: results of the COMPACT Asia-Pacific Study

Authors: K.J. Christiansen, M. Ip, H.B. Ker, M. Mendoza, L.

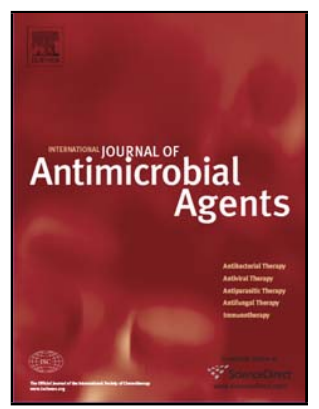

Hsu, P. Kiratisin, A. Chongthaleong, I.S. Redjeki, A.

Quintana, R. Flamm, J. Garcia, M. Cassettari, D. Cooper, P.

Okolo, I. Morrissey

PII:

S0924-8579(10)00349-3

DOI: doi:10.1016/j.ijantimicag.2010.08.002

Reference:

ANTAGE 3406

To appear in:

International

Journal

of

Antimicrobial

Agents

Received date: $\quad 22-4-2010$

Revised date: $\quad 4-8-2010$

Accepted date: $\quad$ 5-8-2010

Please cite this article as: Christiansen KJ, Ip M, Ker HB, Mendoza M, Hsu L, Kiratisin P, Chongthaleong A, Redjeki IS, Quintana A, Flamm R, Garcia J, Cassettari M, Cooper D, Okolo P, Morrissey I, In vitro activity of doripenem and other carbapenems against contemporary Gram-negative pathogens isolated from hospitalised patients in the AsiaPacific region: results of the COMPACT Asia-Pacific Study, International Journal of Antimicrobial Agents (2010), doi:10.1016/j.ijantimicag.2010.08.002

This is a PDF file of an unedited manuscript that has been accepted for publication. As a service to our customers we are providing this early version of the manuscript. The manuscript will undergo copyediting, typesetting, and review of the resulting proof before it is published in its final form. Please note that during the production process errors may be discovered which could affect the content, and all legal disclaimers that apply to the journal pertain. 


\section{In vitro activity of doripenem and other carbapenems against contemporary Gram-negative pathogens isolated from hospitalised patients in the Asia-Pacific region: results of the COMPACT Asia- Pacific Study}
K.J. Christiansen ${ }^{a}$, M. Ip ${ }^{b}$, H.B. Ker ${ }^{c}$, M. Mendoza ${ }^{d}$, L. Hsu ${ }^{e}$, P. Kiratisin ${ }^{f}$, A.

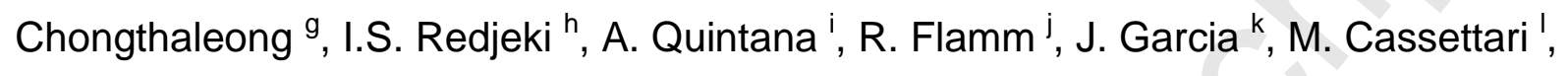
D. Cooper ', P. Okolo ', I. Morrissey ${ }^{1, *}$

a PathWest Laboratory Medicine, Royal Perth Hospital, Perth, Australia

${ }^{\mathrm{b}}$ Chinese University of Hong Kong, Hong Kong SAR

${ }^{c}$ Hospital Raja Permaisuri Bainun, Ipoh, Malaysia

d Philippine General Hospital, Manila, Philippines

e National University Hospital, Singapore

' Siriraj Hospital, Mahidol University, Bangkok, Thailand

${ }^{g}$ King Chulalongkorn Memorial Hospital, Bangkok, Thailand

${ }^{\mathrm{h}}$ RS Hasan Sadikin, Bandung, Indonesia

' Johnson \& Johnson Pharmaceutical Services, New Jersey, USA

j Johnson \& Johnson Pharmaceutical R\&D, New Jersey, USA

k Janssen-Cilag Asia-Pacific, Manila, Republic of the Philippines

${ }^{\prime}$ Quotient Bioresearch Ltd., Fordham, UK

\section{ARTICLE INFO}

Article history:

Received 22 April 2010 
Accepted 5 August 2010

Keywords:

Carbapenem

Doripenem

Pseudomonas

Enterobacteriaceae

Gram-negative

Surveillance

* Corresponding author. Present address: Microbiology, Quotient Bioresearch Ltd., Newmarket Road, Fordham, Cambridgeshire CB7 5WW, UK. Tel.: +44 1638722 960.

E-mail address: lan.Morrissey@quotientbioresearch.com (I. Morrissey). 


\section{ABSTRACT}

The Comparative Activity of Carbapenems Testing (COMPACT) Study was designed to determine the in vitro potency of doripenem compared with imipenem and meropenem against a large number of contemporary Gram-negative pathogens from more than 100 centres across Europe and the Asia-Pacific region and to assess the reliability of Etest methodology for doripenem minimum inhibitory concentration (MIC) determination against these pathogens. Data from eight countries within the AsiaPacific region, which collected 1612 bacterial isolates, are presented here. Etest methodology was found to be a reliable method for MIC determination. Doripenem showed in vitro activity similar to or better than meropenem and at least four-fold better than imipenem against Enterobacteriaceae. Against Pseudomonas aeruginosa, doripenem was also the most active of the three carbapenems in vitro. However, in vitro results do not necessary correlate with clinical outcome. 


\section{Introduction}

Antibiotic resistance amongst Gram-negative nosocomial pathogens continues to increase and to compromise treatment outcomes in the Asia-Pacific region [1,2]. The emergence of Acinetobacter baumannii as a cause of hospital-acquired pneumonia, increasing rates of infections caused by extended-spectrum $\beta$-lactamase (ESBL)producing Enterobacteriaceae such as Klebsiella pneumoniae, and the increasing resistance seen in Pseudomonas aeruginosa are just three examples [3].

Antibiotic resistance rates in some countries in the Asia-Pacific Rim are considerably higher than those in other parts of the world [4], e.g. 52\% of Escherichia coli (ranging from $2.6 \%$ in Australia to $83 \%$ in India) and $52 \%$ of K. pneumoniae (ranging from $7.1 \%$ in Australia to $84 \%$ in India) were found to be ESBL-producers [5].

Infections caused by multidrug-resistant (MDR) Gram-negative pathogens have been associated with increased mortality, increased hospital stay and increased costs [69]. Furthermore, emergence of resistance during treatment of infections caused by pathogens such as $P$. aeruginosa and Enterobacter spp. has a dramatic effect both on outcome and costs $[10,11]$.

Carbapenems now play a prominent therapeutic role, especially in hospitals and patient populations where MDR strains have become prevalent, due to their broad spectrum of activity and their activity against pathogens such as ESBL-producing Enterobacteriaceae, $P$. aeruginosa and Acinetobacter spp. $[3,12,13]$. Doripenem is a new, broad-spectrum, intravenous carbapenem antibiotic. Its in vitro antibacterial spectrum includes meticillin-susceptible staphylococci, streptococci (including 
penicillin-resistant Streptococcus pneumoniae), Enterobacteriaceae, Haemophilus influenzae, $P$. aeruginosa, Moraxella catarrhalis, ceftazidime-susceptible Acinetobacter spp., Bordetella spp., Bacteroides spp., Prevotella spp., Clostridium spp. and other Gram-positive anaerobes, including difficult-to-treat pathogens [14].

Doripenem is approved for the treatment of complicated urinary tract infections and complicated intra-abdominal infections (cIAIs) in the USA, Europe and Asia-Pacific region, and for nosocomial pneumonia (NP) [including ventilator-associated pneumonia (VAP)] both in Europe and several Asia-Pacific countries such as Thailand, Philippines, Malaysia, Australia and Indonesia.

The recommended dose of doripenem $(500 \mathrm{mg})$ is administered as a $1-\mathrm{h}$ infusion three times a day. However, in seriously ill patients (e.g. those with VAP), $500 \mathrm{mg}$ three times a day given as a 4-h infusion is recommended to maximise therapeutic benefit [15]. Pharmacodynamic modelling suggests that prolonged infusion (over 4 h), thus increasing the time interval where drug levels exceed the minimum inhibitory concentration (MIC), would improve coverage of pathogens having a high doripenem MIC (4 mg/L) [16]. Clinical efficacy in patients known or suspected to be infected with pathogens having a high doripenem MIC needs to be confirmed in future clinical studies. Appropriate doripenem dose administration requires adequate epidemiological data and it is therefore essential to collect data on carbapenem MIC distribution against relevant species.

The Comparative Activity of Carbapenems Testing (COMPACT) Study had two objectives: first, to compare the MIC distribution of doripenem with that of imipenem 
and meropenem against Gram-negative pathogens causing serious infections in hospitalised patients, with a particular emphasis on $P$. aeruginosa; and, second, to assess the reliability of Etest methodology for the determination of doripenem MICs for these pathogens. Here we report the findings from the Asia-Pacific region, including Australia, Hong Kong, India, Indonesia, Malaysia, Philippines, Singapore and Thailand.

\section{Materials and methods}

\subsection{Pathogens}

The COMPACT Asia-Pacific Study Group consisted of 27 medical centres in eight countries, including Australia (3 centres), Hong Kong (2 centres), India (3 centres), Indonesia ( 1 centre), Malaysia (3 centres), Philippines (3 centres), Singapore (2 centres) and Thailand (10 centres). Participating centres collected a protocol-defined set and number of consecutive Gram-negative isolates during the latter half of 2008 and early 2009. Non-duplicate isolates were obtained from patients with clAls, bloodstream infections (BSIs) or NP (including VAP). The target number of isolates to be collected at each centre was $30 P$. aeruginosa, 24 Enterobacteriaceae and 6 other Gram-negative pathogens.

\subsection{In vitro investigations}

Each collecting centre determined the MIC of doripenem, imipenem and meropenem against each pathogen collected using Etest methodology (AB BIODISK, Solna, Sweden) following the manufacturer's guidelines. Each centre, with the exception of the centre in Indonesia that was not permitted to export isolates out of the country, 
sent all isolates collected to the central reference laboratory (Quotient Bioresearch Ltd., Fordham, UK) for confirmation of pathogen identification. For quality control purposes, and for validation of Etest methodology for doripenem susceptibility testing, the central reference laboratory determined the MIC of doripenem, imipenem and meropenem by Etest and by broth microdilution (BMD) [17] against all isolates deemed to be resistant to either meropenem or imipenem or non-susceptible to doripenem according to the collecting centre's Etest result interpreted using current Clinical and Laboratory Standards Institute (CLSI) breakpoints for imipenem and meropenem (Table 1) [18] and US Food and Drug Administration (FDA) breakpoints for doripenem (Table 1) as there are no CLSI breakpoints. Further explanation on the rationale for the choice of breakpoints is included in the 'Discussion'. In addition, carbapenem susceptibility by Etest and BMD of a randomly selected $10 \%$ of susceptible isolates was determined. Quality control isolates used were $H$. influenzae ATCC 49766, E. coli ATCC 25922 and P. aeruginosa ATCC 27853. All data were collated and analysed by Quotient Bioresearch Ltd.

\section{Results}

\subsection{Isolates collected}

A total of 1612 isolates were collected over a 6-month period, consisting of 656 Enterobacteriaceae (40.7\%), 784 Pseudomonas spp. (48.6\%) and 172 other Gramnegative isolates (10.7\%). Escherichia coli (38.6\%), K. pneumoniae (35.4\%) and Enterobacter spp. (10.4\%) were the most predominant Enterobacteriaceae collected. Of the Enterobacter spp. isolated, $72.1 \%$ were Enterobacter cloacae. Pseudomonas aeruginosa (99.5\%) was the most commonly isolated Pseudomonas spp., and $A$. 
baumannii (74.4\%) was the most isolated species amongst the other Gram-negatives collected.

Pathogens were most commonly isolated from patients with NP (49.7\%), followed by patients with BSIs (36.6\%) and patients with clAls (13.7\%). Pathogens were isolated from patients in the Intensive Care Unit (ICU) in $38.5 \%$ of cases.

\subsection{Etest minimum inhibitory concentration determination}

The reference laboratory determined the BMD and Etest MICs of 454 isolates, consisting of 306 isolates deemed to be non-susceptible to doripenem or resistant to meropenem or imipenem according to the Etest MIC results (Table 1) generated at each collecting centre as well as for 148 randomly selected isolates that were susceptible to all three carbapenems.

The MIC determined by BMD and by Etest at the central reference laboratory was the same or within one doubling dilution for $89.6 \%$ of isolates tested and was the same or within two doubling dilutions for $98 \%$ of isolates.

The MIC determined by Etest at each centre and at the central reference laboratory was the same or within one doubling dilution for $83.2 \%$ of isolates and the same or within two doubling dilutions for $92.3 \%$ of isolates. Centre Etest MIC values were higher than reference laboratory values in $26.5 \%$ of cases and lower in $20.9 \%$.

Table 2 summarises the in vitro activity of doripenem, imipenem and meropenem by Etest methodology as reported by the collecting centres, and Fig. 1 provides the 
cumulative percentage inhibition curves for Enterobacteriaceae, $A$. baumannii and $P$. aeruginosa.

\subsubsection{Enterobacteriaceae}

Doripenem and meropenem had activity against all Enterobacteriaceae, with $\mathrm{MIC}_{90}$ values (MIC for $90 \%$ of the organisms) of $0.06 \mathrm{mg} / \mathrm{L}$ and $0.12 \mathrm{mg} / \mathrm{L}$, respectively, both being at least four-fold more active than imipenem $\left(\mathrm{MIC}_{90}=0.5 \mathrm{mg} / \mathrm{L}\right)($ Table 2; Fig. 1a). A similar pattern was seen against E. coli, Klebsiella spp. and Enterobacter spp. (Table 2). One E. coli isolate (from India) and one Klebsiella oxytoca isolate (from Singapore) was shown to have a high MIC for all three carbapenems (confirmed by the reference laboratory). One Providencia rettgeri isolate (from Thailand) had a doripenem MIC of $4 \mathrm{mg} / \mathrm{L}$ determined by the source site but this was not confirmed by the reference laboratory (doripenem MIC $0.12 \mathrm{mg} / \mathrm{L}$ at reference laboratory). One E. cloacae isolate (from Thailand) was found to have a doripenem MIC of $1 \mathrm{mg} / \mathrm{L}$ (i.e. just above the susceptible breakpoint) by the local laboratory but an $\mathrm{MIC}<1 \mathrm{mg} / \mathrm{L}$ at the reference laboratory.

The activity of the three carbapenems against Enterobacteriaceae by country is given in Table 3. Doripenem and meropenem were comparable in activity, whilst both were more active than imipenem . Doripenem MICs were $\leq 0.5 \mathrm{mg} / \mathrm{L}$ in isolates from all countries except for the four isolates described above obtained from India, Thailand and Singapore. 


\subsubsection{Other Gram-negative isolates}

Doripenem and meropenem had a lower $\mathrm{MIC}_{50}$ (MIC for $50 \%$ of the organisms) (16 $\mathrm{mg} / \mathrm{L}$ and $32 \mathrm{mg} / \mathrm{L}$, respectively) than imipenem ( $\geq 64 \mathrm{mg} / \mathrm{L})$. All three carbapenems had an $\mathrm{MIC}_{90}$ of $\geq 64 \mathrm{mg} / \mathrm{L}$ against other Gram-negatives combined (Table 2). None of the carbapenems was effective against Stenotrophomonas maltophilia isolates collected, but $6-8$ of 11 isolates of Burkholderia spp. were carbapenem-susceptible (data not shown).

\subsubsection{Pseudomonas aeruginosa}

Doripenem had the lowest $\mathrm{MIC}_{90}$ against $P$. aeruginosa $(8 \mathrm{mg} / \mathrm{L})$, with meropenem and imipenem having MICs of $\geq 64 \mathrm{mg} / \mathrm{L}$ (Table 2). Rates of non-susceptibility to doripenem ( $\mathrm{MIC} \geq 4 \mathrm{mg} / \mathrm{L}$ ) and meropenem (MIC $\geq 8 \mathrm{mg} / \mathrm{L}$ ) were the same $(21.3 \%)$, whilst the rate of non-susceptibility to imipenem (MIC $\geq 8 \mathrm{mg} / \mathrm{mL}$ ) was $24.6 \%$.

The activity of the three carbapenems against $P$. aeruginosa by country is given in Table 3.

Pseudomonas aeruginosa isolates from ICU patients tended to have higher carbapenem MICs than those collected outside of the ICU: the $\mathrm{MIC}_{90}$ for all carbapenems in the ICU was $\geq 64 \mathrm{mg} / \mathrm{L}$ compared with $4 \mathrm{mg} / \mathrm{L}$ for doripenem and 16 $\mathrm{mg} / \mathrm{L}$ for the other two carbapenems outside the ICU (data not shown). Of the $P$. aeruginosa isolated from patients within the ICU, 30.0\% were doripenem nonsusceptible compared with $22.4 \%$ of those from outside the ICU (data not shown; see Table 1 for breakpoints). 
The carbapenems were equally active against $P$. aeruginosa isolates from BSIs, clAls and NP (data not shown).

\subsection{Carbapenem resistance}

Using CLSI breakpoints in place at the time of the study (Table 1) [18], ca. 17-18\% of isolates were non-susceptible to imipenem or meropenem. Currently, the CLSI have not published breakpoints for doripenem, therefore using FDA breakpoints (only susceptible category published), 277 isolates (17.2\%) were non-susceptible to doripenem (see Table 1 for breakpoints).

Almost full susceptibility was seen against the Enterobacteriaceae, with nonsusceptibility rates $<1 \%$ for all carbapenems (data not shown).

All S. maltophilia $(n=8)$ were non-susceptible to all three carbapenems (likely due to production of metallo- $\beta$-lactamase) and a high percentage of non-susceptibility was seen in Burkholderia spp., Acinetobacter spp. and Pseudomonas spp.

Eighty-six isolates (62.8\%) of Acinetobacter spp. were resistant (MIC $\geq 16 \mathrm{mg} / \mathrm{L}$ ) to both imipenem and meropenem and had high doripenem MICs (4 mg/L to $\geq 16 \mathrm{mg} / \mathrm{L})$.

One hundred and twenty-four $P$. aeruginosa isolates (15.9\%) were resistant (MIC $\geq$ $16 \mathrm{mg} / \mathrm{L}$ ) to both imipenem and meropenem and all but one of these isolates were also doripenem non-susceptible. 


\section{Discussion}

The in vitro activity of the three carbapenems was determined in this study using Etest methodology. The Etest and BMD MIC values generated by the reference laboratory were in high agreement, and the Etest MIC values generated by each collecting centre were in high agreement with those of the reference laboratory. Etest methodology therefore appears to be a reliable method for doripenem MIC determination.

The in vitro activity of doripenem against Enterobacteriaceae was essentially no different to that of meropenem and was at least four-fold more potent than that of imipenem, including against the important pathogens E. coli and K. pneumoniae. A high percentage of these species are ESBL-producers in Asia-Pacific countries [5] and bacteraemic patients with ESBL-positive strains have been shown to have significantly higher average hospital costs, longer median hospital stays following onset of bacteraemia ( 11 days vs. 5 days; $P<0.001$ ) and higher in-hospital mortality (35\% vs. $18 \% ; P=0.01)$ compared with patients infected with non-ESBL-producing strains [8].

Doripenem had the lowest MIC distribution of the three carbapenems against $P$. aeruginosa regardless of whether the isolates were from patients within or outside the ICU and regardless of the type of infection. It is important to note, however, that there was a high proportion of isolates in the collection from Thailand, which may well affect the results of this study. Comparing Thailand with the other countries represented in this study would overestimate resistance in the region because Thailand has higher than average carbapenem MICs. 
Susceptibility analyses in this study were evaluated using breakpoints developed by the internationally recognised performance standards developing organisation (CLSI) at the time of study [18], which have not changed in the recent standards update [19]. The exception to this was doripenem, as there are no doripenem breakpoints in the CLSI standards. Organisations that establish breakpoints base their breakpoint decisions on the evaluation of MIC population distributions of organisms to include knowledge of resistance mechanisms and wild-type distributions, pharmacokinetics/pharmacodynamics, and correlation of MIC with clinical outcome. The organisations evaluate similar types of data but, owing to varying emphasis on key data sets, they may come to different conclusions regarding specific breakpoints. For example, for doripenem the European Committee on Antimicrobial Susceptibility Testing (EUCAST) breakpoints for $P$. aeruginosa and Enterobacteriaceae are susceptible $\leq 1 \mathrm{mg} / \mathrm{L}$, intermediate $2-4 \mathrm{mg} / \mathrm{L}$ and resistant $\geq 8 \mathrm{mg} / \mathrm{L}$, whilst the FDA breakpoints are susceptible $\leq 2 \mathrm{mg} / \mathrm{L}$ for $P$. aeruginosa and $\leq 0.5 \mathrm{mg} / \mathrm{L}$ for Enterobacteriaceae, with no intermediate/resistant categories defined. Other regulatory authorities around the world may also differ in how they establish breakpoints. The choice of the FDA breakpoint for doripenem in this study is a conservative approach as it is two-fold lower than those for meropenem and imipenem for $P$. aeruginosa and eight-fold lower for Enterobacteriaceae. It is pertinent to note that very recently the CLSI have published an update of the performance standards for antimicrobial susceptibility testing [20], where new carbapenem breakpoints for Enterobacteriaceae are presented, with reduced susceptible, intermediate and resistant breakpoints of $\leq 1,2$ and $\geq 4 \mathrm{mg} / \mathrm{L}$, respectively, for all three carbapenems utilised in this study. Re-analysis of the data 
presented here for the Enterobacteriaceae has little effect on doripenem or meropenem non-susceptibility $(0.3-0.6 \%)$, but imipenem non-susceptibility increases from $0.2 \%$ to $2 \%$ (data not shown). At present, no changes to $P$. aeruginosa CLSI breakpoints have been made, but if a similar change were introduced the relative shift in susceptibility would be in favour of doripenem.

Overall, non-susceptibility to meropenem and imipenem or doripenem was ca. 17$18 \%$ with little or no resistance observed in the Enterobacteriaceae. Nine percent of imipenem-resistant and $1 \%$ of meropenem-resistant isolates were doripenemsusceptible.

There was greater differentiation between the carbapenems against $P$. aeruginosa than with other bacterial species. Imipenem resistance in $P$. aeruginosa varied from country to country. The lowest rate was in Indonesia (5.1\%) but this increased to as high as $35-38 \%$ in Thailand and India. As the rate of imipenem resistance increased, so did the resistance rate observed for meropenem and doripenem.

Pseudomonas aeruginosa is one of the leading causes of hospital-acquired infections for which treatment options are limited [21], and MDR $P$. aeruginosa has a significant impact on mortality and costs $[6,7,10]$. In addition, an increased carbapenem (imipenem and meropenem) MIC will clearly reduce the therapeutic options for $P$. aeruginosa infections where high levels of antibiotic resistance are common $[5,7]$. It has been postulated that extending the infusion time of a more active agent may overcome these difficulties by increasing the likelihood that the pharmacodynamic target is attained [13]. Furthermore, in vivo simulations support 
the use of prolonged infusions of doripenem at $1 \mathrm{~g}$ or $2 \mathrm{~g}$ doses as a potential treatment for $P$. aeruginosa isolates with raised doripenem MICs [22].

Although the in vitro activity of doripenem against Pseudomonas appears to be the best of the three carbapenems tested, geography and whether the patient is in or outside the ICU was shown to impact this activity. A real-time surveillance programme monitoring the susceptibility and MICs of these bacterial pathogens at the country or healthcare centre level appears to be a necessary tool to guide empirical treatment effectively. The Etest method for MIC determination is a rapid, convenient and reliable method for use in the clinical diagnostic laboratory.

Confirmatory testing using a reference BMD method could be performed as required. Because in vitro data do not always extrapolate to the clinical setting, prospective controlled clinical trials are needed to demonstrate the efficacy of different infusion regimens or administration. Furthermore, there is generally a high prevalence of antibiotic resistance in Gram-negative bacteria in the Asia-Pacific region that will continue to be a problem for clinicians. These challenges will need to be overcome by alternative strategies with existing agents such as dosing manipulation (e.g. higher doses and/or prolonged infusion with doripenem) or combination therapy.

\section{Acknowledgments}

The authors would like to thank Lucie Farmer and Sarah Farrell (Quotient Bioresearch Ltd., Fordham, UK) for laboratory support as well as Mike Stek for scientific and strategic support. They also thank the many investigators in each country who participated in the collection of isolates (COMPACT Asia-Pacific Study Group): J. Turnidge and J. Bell (Women's and Children's Hospital, Adelaide, 
Australia); T. Gottleib and G. Funnell (Concord Hospital, Sydney, Australia); G. Coombs (Royal Perth Hospital, Perth, Australia); R. Leung (Queen Mary Hospital, Hong Kong); R. Kelkar (Tata Memorial Hospital, Mumbai, India); R. Rao (Apollo Hospitals, Hyderabad, India); R. Sardana (Indraprastha Apollo Hospital, New Delhi, India); O.E. Tampubolon (RS Siloam Karawaci, Tangerang, Indonesia); M. Nazri (Hospital Kuala Lumpur, Malaysia); G. Rajasekaran (Hospital Sultanah Aminah, Johor Bahru, Malaysia); D. Tiu (St Luke's Medical Center, Quezon City, Philippines); E. Lagamayo and R.G. Bergantin (University of Santo Tomas Hospital, Manila, Philippines); T.Y. Tan (Changi General Hospital, Singapore); R.N. Deepak (Singapore General Hospital, Singapore); V. Sooksaart (Bumrungrad International Hospital, Bangkok, Thailand); S. Thunyaharn (Phramongkutklao Hospital, Bangkok, Thailand); S. Rahule (Rajavithi Hospital, Bangkok, Thailand); J. Visalsawadi (Maharat Nakhon Ratchasima Hospital, Nakhon Ratchasima, Thailand); Y. Kotipan (Bangkok Hospital, Bangkok, Thailand); N. Srisuraj (Khon Kaen Hospital, Khon Kaen, Thailand); U. Klamem (Police General Hospital, Bangkok, Thailand); and W. Srichanta (Saraburi Hospital, Saraburi, Thailand).

\section{Funding}

The research outlined in this publication was funded by Janssen-Cilag.

\section{Competing interests}

Quotient Bioresearch Ltd. (Fordham, UK) carries out research on behalf of numerous pharmaceutical companies for the development of new antimicrobials.

\section{Ethical approval}


Not required. 


\section{References}

[1] Nan-Yao L, Hsin-Chun L, Nai-Ying K, Chia-Ming C, Hsin-I S, Chi-Jung W, et al. Clinical and economic impact of multidrug resistance in nosocomial Acinetobacter baumannii bacteremia. Infect Control Hosp Epidemiol 2007;28:713-9.

[2] Prashanth K, Badrinath S. Nosocomial infections due Acinetobacter species: clinical findings, risk and prognostic factors. Indian J Med Microbiol 2006;24:39_ 44.

[3] Slama TG. Gram-negative antibiotic resistance: there is a price to pay. Crit Care 2008;12(Suppl 4):S4.

[4] Bouchillon SK, Iredell JR, Barkham T, Lee K, Dowzicky MJ. Comparative in vitro activity of tigecycline and other antimicrobials against Gram-negative and Grampositive organisms collected from the Asia-Pacific Rim as part of the Tigecycline Evaluation and Surveillance Trial (TEST). Int J Antimicrob Agents 2009;33:130-6.

[5] Bell JM, Turnidge JD, Fritsche TR, Jones RN. Doripenem activity against leading bacterial pathogens in the Asia-Pacific region: report from the SENTRY Antimicrobial Surveillance Program (2006). In: 6th International Symposium on Antimicrobial Agents and Resistance (ISAAR); 7-9 March 2007; Singapore. Poster NA33.

[6] Harris A, Torres-Viera C, Venkataraman L, DeGirolami P, Samore M, Carmeli Y. Epidemiology and clinical outcomes of patient with multiresistant Pseudomonas aeruginosa. Clin Infect Dis 1999;28:1128-33.

[7] Tacconelli E, Tumbarello M, Bertagnolio S, Citton R, Spanu T, Fadda G, et al. Multidrug-resistant Pseudomonas aeruginosa bloodstream infections: analysis of trends in prevalence and epidemiology. Emerg Infect Dis 2002;8:220-1. 
[8] Schwaber MJ, Navon-Venezia S, Kaye KS, Ben-Ami R, Schwartz D, Carmeli Y. Clinical and economic impact of bacteremia with extended-spectrum- $\beta$-lactamaseproducing Enterobacteriaceae. Antimicrob Agents Chemother 2006;50:1257-62.

[9] Kwon KT, Oh WS, Song J-H, Chang HH, Jung SI, Kim SW, et al. Impact of imipenem resistance on mortality in patients with Acinetobacter bacteremia. $\mathrm{J}$ Antimicrob Chemother 2007;59:525-30.

[10] Carmeli Y, Troillet N, Karchmer AW, Samore MH. Health and economic outcomes of antibiotic resistance in Pseudomonas aeruginosa. Arch Intern Med 1999;159:1127-32.

[11] Cosgrove SE, Kaye KS, Eliopoulous GM, Carmeli Y. Health and economic outcomes of the emergence of third-generation cephalosporin resistance in Enterobacter species. Arch Intern Med 2002;162:185-90.

[12] Jones RN, Huynh HK, Biedenbach DJ, Fritsche TR, Sader HS. Doripenem (S4661), a novel carbapenem: comparative activity against contemporary pathogens including bactericidal action and preliminary in vitro methods evaluations. J Antimicrob Chemother 2004;54:144-54.

[13] Nicolau DP. Carbapenems: a potent class of antibiotics. Expert Opin Pharmacother 2008;9:23-37.

[14] Tsuji M, Ishii Y, Ohno A, Miyazaki S, Yamaguchi K. In vitro and in vivo antibacterial activities of S-4661, a new carbapenem. Antimicrob Agents Chemother 1998;42:94-9.

[15] Chastre J, Wunderink R, Prokocimer P, Lee M, Kaniga K, Friedland I. Efficacy and safety of intravenous infusion of doripenem versus imipenem in ventilatorassociated pneumonia: a multicenter, randomized study. Crit Care Med 2008;36:1089-96. 
[16] Bhavnani S, Hammel J, Cirincione B, Wikler MA, Ambrose PG. Use of pharmacokinetic-pharmacodynamic target attainment analyses to support phase 2 and 3 dosing strategies for doripenem. Antimicrob Agents Chemother 2005;49:3944-7.

[17] Clinical and Laboratory Standards Institute. Methods for dilution antimicrobial susceptibility tests for bacteria that grow aerobically; approved standard. 7th ed. Document M7-A7. Wayne, PA: CLSI; 2006.

[18] Clinical and Laboratory Standards Institute. Performance standards for antimicrobial susceptibility testing. Nineteenth informational supplement. Document M100-S19. Wayne, PA: CLSI; 2009.

[19] Clinical and Laboratory Standards Institute. Performance standards for antimicrobial susceptibility testing. Twentieth informational supplement. Document M100-S20. Wayne, PA: CLSI; 2010.

[20] Clinical and Laboratory Standards Institute. Performance standards for antimicrobial susceptibility testing; update. Document M100-S20-U. Wayne, PA: CLSI; 2010.

[21] American Thoracic Society; Infectious Diseases Society of America. Guidelines for the management of adults with hospital-acquired, ventilatorassociated, and healthcare-associated pneumonia. Am J Respir Crit Care Med $2005 ; 171: 388-416$.

[22] Crandon JL, Bulik CC, Nicolau DP. In vivo efficacy of 1- and 2-gram human simulated prolonged infusions of doripenem against Pseudomonas aeruginosa. Antimicrob Agents Chemother 2009;53:4352-6. 
Fig. 1. Cumulative minimum inhibitory concentration (MIC) distribution for doripenem, imipenem and meropenem against (a) Enterobacteriaceae, (b) Acinetobacter baumannii and (C) Pseudomonas aeruginosa. 


\section{Table 1}

Breakpoints (in $\mathrm{mg} / \mathrm{L}$ ) used to determine susceptibility of isolates for minimum inhibitory concentration testing

\begin{tabular}{|c|c|c|c|c|c|c|c|c|c|}
\hline \multirow[t]{3}{*}{ Isolates } & \multicolumn{3}{|l|}{ FDA } & \multicolumn{6}{|c|}{ CLSI } \\
\hline & \multicolumn{3}{|c|}{ Doripenem } & \multicolumn{3}{|c|}{ Imipenem } & \multicolumn{3}{|c|}{ Meropenem } \\
\hline & $\mathrm{S}$ & $\mathrm{I}$ & $\mathrm{R}$ & $\mathrm{S}$ & 1 & $\mathrm{R}$ & $\mathrm{S}$ & 1 & $\mathrm{R}$ \\
\hline Pseudomonas aeruginosa & $\leq 2$ & - & - & $\leq 4$ & 8 & $\geq 16$ & $\leq 4$ & 8 & $\geq 16$ \\
\hline Enterobacteriaceae & $\leq 0.5$ & - & - & $\leq 4$ & 8 & $\geq 16$ & $\leq 4$ & 8 & $\geq 16$ \\
\hline Acinetobacter spp. (A. baumanniI) & $\leq 1$ & - & - & $\leq 4$ & 8 & $\geq 16$ & $\leq 4$ & 8 & $\geq 16$ \\
\hline Stenotrophomonas maltophilia & $\leq 2$ & - & - & $\leq 4$ & 8 & $\geq 16$ & $\leq 4$ & 8 & $\geq 16$ \\
\hline Burkholderia cepacia & $\leq 2$ & - & - & $\leq 4$ & 8 & $\geq 16$ & $\leq 4$ & 8 & $\geq 16$ \\
\hline Other non-Enterobacteriaceae & $\leq 1$ & - & - & $\leq 4$ & 8 & $\geq 16$ & $\leq 4$ & 8 & $\geq 16$ \\
\hline Haemophilus influenzae & $\leq 1$ & - & - & $\leq 4$ & - & - & $\leq 0.5$ & - & - \\
\hline
\end{tabular}

FDA, US Food and Drug Administration; CLSI, Clinical and Laboratory Standards Institute; S, susceptible, I, intermediate; R, resistant. 


\section{Table 2}

Summary minimum inhibitory concentration (MIC) data for doripenem (DOR), imipenem (IPM) and meropenem (MEM) against Gram-negative bacteria as determined using Etest methodology by the collecting centres

\begin{tabular}{|c|c|c|c|c|}
\hline \multirow[t]{2}{*}{ Isolates $(n)$} & \multirow{2}{*}{$\begin{array}{l}\text { Antimicrobial } \\
\text { agent }\end{array}$} & \multicolumn{2}{|c|}{ MIC (mg/L) } & 2 \\
\hline & & $\mathrm{MIC}_{50}$ & $\mathrm{MIC}_{90}$ & Range \\
\hline \multirow[t]{3}{*}{ Enterobacteriaceae (656) } & DOR & 0.03 & 0.06 & $0.008-8^{a, b}$ \\
\hline & IPM & 0.25 & 0.5 & $0.008-8^{a, b}$ \\
\hline & MEM & 0.03 & 0.12 & $0.008-16^{a, b}$ \\
\hline \multirow[t]{3}{*}{ Escherichia coli (253) } & DOR & 0.015 & 0.06 & $0.008-8^{a}$ \\
\hline & IPM & 0.12 & 0.25 & $0.015-8^{a}$ \\
\hline & MEM & 0.03 & 0.06 & $0.008-16^{a}$ \\
\hline \multirow[t]{3}{*}{ Klebsiella spp. (243) } & DOR & 0.03 & 0.06 & $0.008-4^{b}$ \\
\hline & IPM & 0.25 & 0.25 & $0.008-2^{b}$ \\
\hline & MEM & 0.03 & 0.06 & $0.008-8^{b}$ \\
\hline \multirow[t]{3}{*}{ Enterobacter spp. (68) } & DOR & 0.03 & 0.25 & $0.015-1$ \\
\hline & IPM & 0.25 & 1 & $0.015-4$ \\
\hline & MEM & 0.03 & 0.25 & $0.015-2$ \\
\hline \multirow[t]{3}{*}{ Salmonella spp. (30) } & DOR & 0.015 & 0.03 & $0.008-0.25$ \\
\hline & IPM & 0.12 & 0.25 & $0.03-1$ \\
\hline & MEM & 0.015 & 0.03 & $0.008-0.03$ \\
\hline \multirow[t]{3}{*}{ Proteus spp. (21) } & DOR & 0.06 & 0.25 & $0.03-0.25$ \\
\hline & IPM & 0.5 & 2 & $0.25-4$ \\
\hline & MEM & 0.06 & 0.25 & $0.03-0.5$ \\
\hline \multirow[t]{3}{*}{ Serratia spp. (13) } & DOR & - & - & $0.015-0.12$ \\
\hline & IPM & - & - & $0.25-1$ \\
\hline & MEM & - & - & $0.03-0.12$ \\
\hline \multirow[t]{3}{*}{ Citrobacter spp. (10) } & DOR & - & - & $0.015-0.5$ \\
\hline & IPM & - & - & $0.12-2$ \\
\hline & MEM & - & - & $0.015-0.5$ \\
\hline Pseudomonas aeruginosa (780) & DOR & 0.25 & 8 & $\begin{array}{l}0.002 \text { to } \\
\geq 64\end{array}$ \\
\hline
\end{tabular}




\begin{tabular}{|c|c|c|c|c|}
\hline & IPM & 1 & $\geq 64$ & 0.06 to $\geq 64$ \\
\hline & MEM & 0.5 & $\geq 64$ & 0.008 to \\
\hline & & & & $\geq 64$ \\
\hline \multirow{5}{*}{$\begin{array}{l}\text { Other Gram-negative isolates } \\
(172)\end{array}$} & DOR & 16 & $\geq 64$ & 0.008 to \\
\hline & & & & $\geq 64$ \\
\hline & IPM & $\geq 64$ & $\geq 64$ & 0.015 to \\
\hline & & & & 34 \\
\hline & MEM & 32 & $\geq 64$ & 0.015 to \\
\hline \multirow[t]{5}{*}{ Acinetobacter baumannii (128) } & DOR & 32 & $\geq 64$ & 0.008 to \\
\hline & IPM & $\geq 64$ & $\geq 64$ & 0.015 to \\
\hline & & & & $\geq 64$ \\
\hline & MEM & & $\geq 64$ & 0.015 to \\
\hline & & & & $\geq 64$ \\
\hline \multirow[t]{3}{*}{ Burkholderia spp. (11) } & DOR & - & - & 0.12 to $\geq 64$ \\
\hline & IPM & - & - & 0.25 to $\geq 64$ \\
\hline & MEM & - & - & 0.12 to $\geq 64$ \\
\hline
\end{tabular}

$\mathrm{MIC}_{50 / 90}$, MICs for $50 \%$ and $90 \%$ of the organisms, respectively.

${ }^{a}$ One E. coli isolate was less susceptible to all three carbapenems (confirmed by the reference laboratory), with DOR, IPM and MEM MIC values of 8,8 and $16 \mathrm{mg} / \mathrm{L}$; the highest MICs excluding this isolate were $0.5,1$ and $0.5 \mathrm{mg} / \mathrm{L}$, respectively.

${ }^{\mathrm{b}}$ One $K$. oxytoca isolate was less susceptible to all three carbapenems (confirmed by the reference laboratory), with DOR, IPM and MEM MIC values 4, 2 and $8 \mathrm{mg} / \mathrm{L}$; the highest MICs excluding this isolate were $0.5,1$ and $0.5 \mathrm{mg} / \mathrm{L}$, respectively. 


\section{Table 3}

Carbapenem minimum inhibitory concentrations (MICs) (mg/L) against Pseudomonas aeruginosa and Enterobacteriaceae isolates evaluated by country

\begin{tabular}{|c|c|c|c|c|c|c|c|c|c|}
\hline \multirow[t]{2}{*}{ Country } & \multirow[t]{2}{*}{ Carbapenem } & \multicolumn{4}{|c|}{$P$. aeruginosa $(n=780)$} & \multicolumn{4}{|c|}{ Enterobacteriaceae $(n=656)$} \\
\hline & & $n$ & $\mathrm{MIC}_{50}$ & $\mathrm{MIC}_{90}$ & Range & $n$ & $\mathrm{MIC}_{50}$ & $\mathrm{MIC}_{90}$ & Range \\
\hline \multirow[t]{6}{*}{ Australia } & DOR & 87 & 0.25 & 4 & 0.03 to & 82 & 0.015 & 0.03 & $0.008-$ \\
\hline & & & & & $\geq 64$ & & & & 0.12 \\
\hline & IPM & & 1 & 8 & 0.06 to & & 0.25 & 0.25 & $0.12-2$ \\
\hline & & & & & $\geq 64$ & & & & \\
\hline & MEM & & 0.5 & 8 & 0.015 to & & 0.03 & 0.03 & $0.008-$ \\
\hline & & & & & $\geq 64$ & & & & 0.25 \\
\hline \multirow{5}{*}{$\begin{array}{l}\text { Hong } \\
\text { Kong }\end{array}$} & DOR & 59 & 0.25 & 2 & $0.06-8$ & 47 & 0.03 & 0.12 & $0.015-$ \\
\hline & & & & & & & & & 0.5 \\
\hline & IPM & & 1 & 2 & 0.5 to & & 0.25 & 1 & $0.03-4$ \\
\hline & MEM & & 0.25 & 2 & $0.03-16$ & & 0.03 & 0.12 & $0.015-$ \\
\hline & & & & & & & & & 0.25 \\
\hline \multirow[t]{6}{*}{ India } & DOR & 66 & 0.25 & $\geq 64$ & 0.03 to & 65 & 0.015 & 0.06 & $0.008-8$ \\
\hline & & & & & $\geq 64$ & & & & \\
\hline & IPM & & 2 & $\geq 64$ & 0.12 to & & 0.12 & 0.25 & $0.06-8$ \\
\hline & & & & & $\geq 64$ & & & & \\
\hline & MEM & & 0.5 & $\geq 64$ & 0.06 to & & 0.03 & 0.06 & $0.008-$ \\
\hline & & & & & $\geq 64$ & & & & 16 \\
\hline \multirow[t]{6}{*}{ Indonesia } & DOR & 39 & 0.25 & 4 & 0.03 to & 36 & 0.06 & 0.25 & $0.008-$ \\
\hline & & & & & $\geq 64$ & & & & 0.5 \\
\hline & IPM & & 2 & 4 & 0.12 to & & 0.25 & 1 & $0.03-4$ \\
\hline & & & & & $\geq 64$ & & & & \\
\hline & MEM & & 0.5 & 4 & 0.03 to & & 0.06 & 0.5 & $0.008-1$ \\
\hline & & & & & $\geq 64$ & & & & \\
\hline \multirow[t]{2}{*}{ Malaysia } & DOR & 89 & 0.25 & 2 & 0.015 to & 71 & 0.03 & 0.06 & $0.008-$ \\
\hline & & & & & $\geq 64$ & & & & 0.5 \\
\hline
\end{tabular}




\begin{tabular}{|c|c|c|c|c|c|c|c|c|c|}
\hline & IPM & & 1 & 16 & $\begin{array}{l}0.12 \text { to } \\
\geq 64\end{array}$ & & 0.25 & 0.5 & $0.12-2$ \\
\hline & MEM & & 0.25 & 4 & $\begin{array}{c}0.03 \text { to } \\
\geq 64\end{array}$ & & 0.03 & 0.12 & $0.015-1$ \\
\hline \multirow[t]{3}{*}{ Philippines } & DOR & 85 & 0.25 & 8 & $\begin{array}{c}0.03 \text { to } \\
\geq 64\end{array}$ & 67 & 0.03 & 0.12 & $\begin{array}{c}0.008- \\
0.5\end{array}$ \\
\hline & IPM & & 2 & 32 & $\begin{array}{c}0.06 \text { to } \\
\geq 64\end{array}$ & & 0.25 & 0.5 & $0.008-1$ \\
\hline & MEM & & 0.5 & 32 & $\begin{array}{c}0.008 \text { to } \\
\geq 64\end{array}$ & & 0.03 & 0.12 & $\begin{array}{c}0.008- \\
0.5\end{array}$ \\
\hline \multirow[t]{3}{*}{ Singapore } & DOR & 60 & 0.25 & 8 & $\begin{array}{l}0.015 \text { to } \\
\geq 64\end{array}$ & 48 & 0.03 & 0.12 & $0.015-4$ \\
\hline & IPM & & 1 & $\geq 64$ & $\begin{array}{l}0.25 \text { to } \\
\geq 64\end{array}$ & & 0.25 & 0.5 & $0.12-2$ \\
\hline & MEM & & 0.5 & $\geq 64$ & 0.008 to & & 0.03 & 0.12 & $0.015-8$ \\
\hline \multirow[t]{3}{*}{ Thailand } & DOR & 295 & 0.5 & 16 & $\begin{array}{l}0.002 \text { to } \\
\geq 64\end{array}$ & 240 & 0.03 & 0.06 & $0.008-4$ \\
\hline & IPM & & 2 & $\geq 64$ & $\begin{array}{c}0.12 \text { to } \\
\geq 64\end{array}$ & & 0.12 & 0.25 & $0.015-2$ \\
\hline & MEM & & 0.5 & $\geq 64$ & $\begin{array}{c}0.03 \text { to } \\
\geq 64\end{array}$ & & 0.03 & 0.06 & $0.008-2$ \\
\hline
\end{tabular}

$\mathrm{MIC}_{50 / 90}$, MICs for $50 \%$ and $90 \%$ of the organisms, respectively; DOR, doripenem;

IPM, imipenem; MEM, meropenem. 
(a) Enterobacteriaceae $(\mathrm{N}=656)$

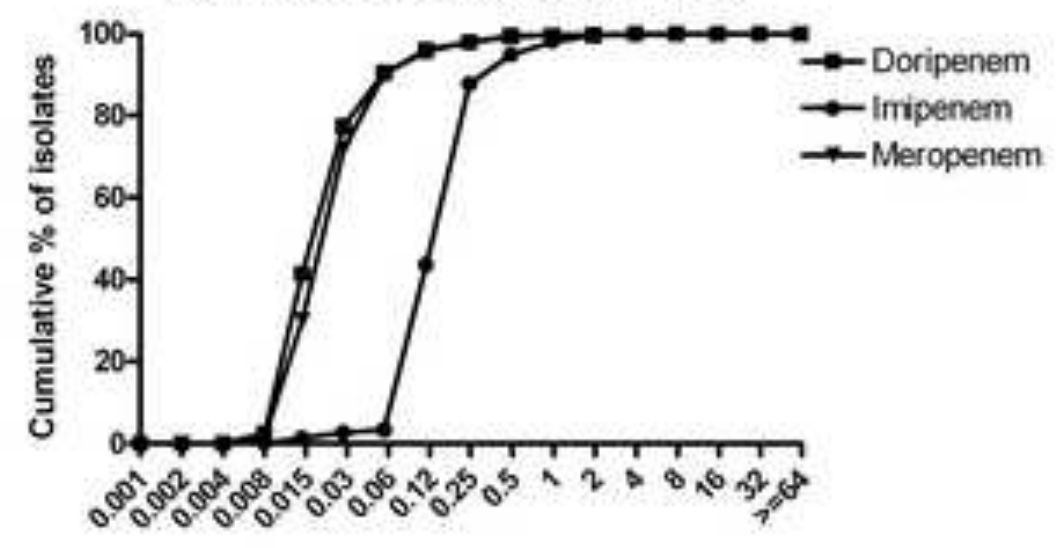

Carbapenem MaC (mg/L)

(b) A. baumannii ( $n=128$ )

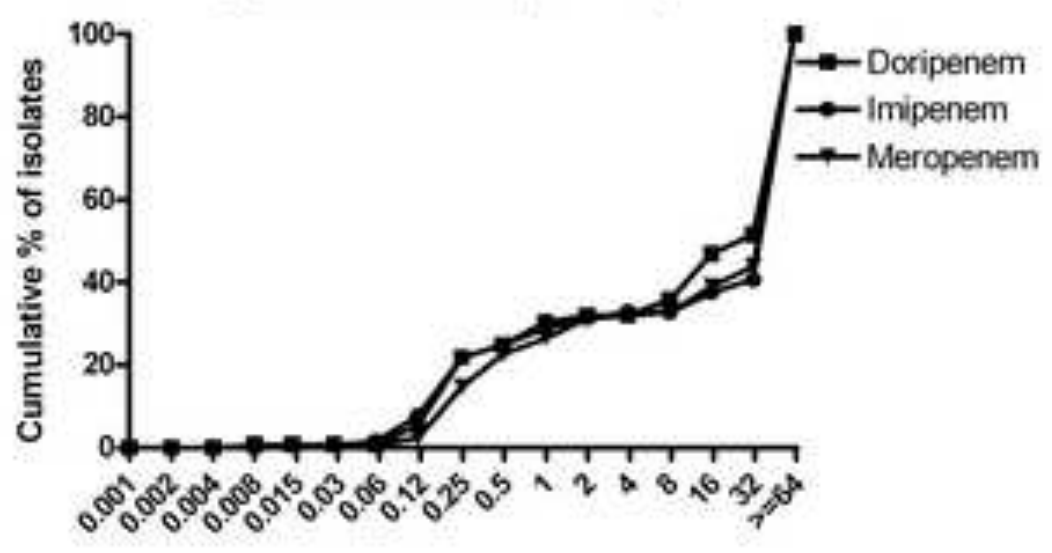

Carbapenem MIC (mg/L)

(c) P. aeruginosa $(n=780)$

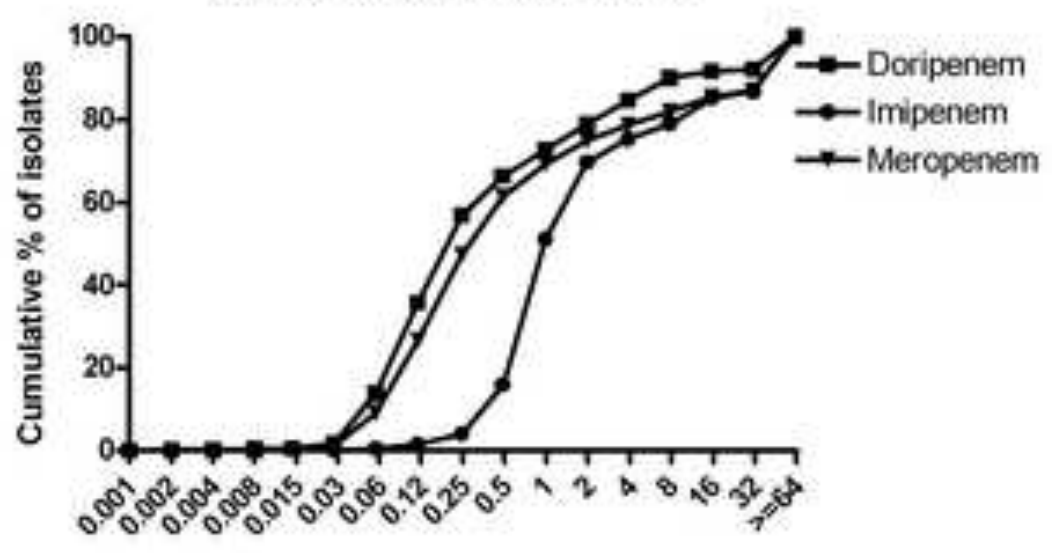

Carbapenem MIC (mg/L) 